\title{
Characteristics and Sinterability of Ceria Stabilized Zirconia Nanoparticles Prepared by Chemical Methods
}

\author{
Jānis GRABIS *, Dzidra JANKOVIČA, Ints ŠTEINS, Māra LUBĀNE, Inta SĪPOLA \\ Institute of Inorganic Chemistry, Faculty of Material Sciences and Applied Chemistry, Rīga Technical University, Kalku 1, \\ Riga, LV-1658, Latvia
}

crossref http://dx.doi.org/10.5755/j01.ms.24.3.18288

Received 31 May 2017; accepted 10 November 2017

\begin{abstract}
Microwave assisted and molten salts synthesis were extended for preparation of ceria (10 mol\%; $15 \mathrm{~mol} \%)$ stabilized zirconia and their parameters and sinterability were compared with that of particles prepared by the sol-gel combustion method. As-prepared powders by using microwave assisted and sol-gel combustion synthesis contained single tetragonal $\mathrm{ZrO}_{2}$ phase but powders prepared by molten salts combustion method contained two ceria-stabilized tetragonal phases with different content of ceria. The crystallite size of the as-prepared zirconia phases was in the range of $3.2-9.4 \mathrm{~nm}$ and the average particles size is in the range of 7.6-24.6 nm depending on the synthesis method. Additional calcination of the powders up to $1000{ }^{\circ} \mathrm{C}$ led to increase of crystallite size in the range of $19-25 \mathrm{~nm}$ and decrease of specific surface area in the range of $18-21 \mathrm{~m}^{2} / \mathrm{g}$ and partial formation of monoclinic phase of $\mathrm{ZrO}_{2}$. Bulk materials with fine-grained microstructure $(0.8-1.6 \mu \mathrm{m})$ and density in the range of $95.2-97.2 \%$ were obtained by spark plasma sintering at $1280-1310^{\circ} \mathrm{C}$ during $3 \mathrm{~min}$. Nanoparticles prepared by microwave assisted synthesis showed better sinterability and higher density.

Keywords: zirconia, ceria, synthesis of nanoparticles, spark plasma sintering.
\end{abstract}

\section{INTRODUCTION}

Ceria stabilized zirconia polycrystalline ceramics have been investigated extensively due to their better stability relate to yttria-stabilized zirconia in the moist environment [1] and the thermal expansion coefficient matching that of the iron-alloys [2]. However, mechanical characteristics of ceria-stabilized zirconia depend on its density, grain-size and presence of the transformable tetragonal phase $[2,3]$ which depends on the used preparation route of powders and their sintering method. Nanosized powders with a high specific surface area with definite phase composition and fast their sintering methods are required for manufacturing of dense fine-grained zirconia based ceramic. Several chemical methods such as spray-drying [2], hydrothermal [4], sol-gel [5,6], sol-gel-combustion [6,7,8], coprecipitation [8] have been developed for preparation of nanosized stabilized zirconia nanopowders.

Each preparation method of ceria stabilized zirconia nanoparticles has its characteristic advantages and disadvantages that relate mainly to complexity of the process, expensive precursors, production rate and cost as well as to size distribution of the particles and presence of agglomerates.

Present trends in technology are directed to development of effective and environmentally friendly preparation methods of nanoparticles. From this point of view, fast microwave assisted and solvent free molten salt synthesis [9], which has been successful applied for producing several nanoparticles, is a promising preparation method of ceria stabilized zirconia.
The aim of the present work was extension of microwave assisted and molten salt preparation methods for the synthesis of ceria stabilized zirconia nanoparticles and comparison of the characteristics and sinterability of the obtained powders with that of the particles produced by the sol-gel combustion method.

\section{EXPERIMENTAL}

Synthesis was performed by using the following analytical reagent grade chemicals: $\mathrm{ZrOCl}_{2} .8 \mathrm{H}_{2} \mathrm{O}$, $\mathrm{Ce}\left(\mathrm{NO}_{3}\right)_{2} \cdot 6 \mathrm{H}_{2} \mathrm{O}$, urea $\mathrm{CH}_{4} \mathrm{~N}_{2} \mathrm{O}$, glycine $\mathrm{C}_{2} \mathrm{H}_{5} \mathrm{NO}_{3}, \mathrm{NaCl}-$ $\mathrm{NaNO}_{3}$.

For molten salts (MS) synthesis, the zirconium and cerium salts were mixed and grounded with a definite amount of $\mathrm{NaCl}$ and $\mathrm{NaNO}_{3}$. The mixture of the zirconium and cerium salts contained 10 or $15 \mathrm{~mol} \%$ of $\mathrm{CeO}_{2}$. The molar ratio of $\mathrm{Zr}$ and $\mathrm{Ce}$ to $\mathrm{Na}$ salts was in the range of $0.12-0.25$. A crucible with precursors was put into the furnace and heated at $400-800{ }^{\circ} \mathrm{C}$ high temperature during $2 \mathrm{~h}$. The melting temperature of $\mathrm{Na}$ salts was changed by varying the ratio of sodium salts. The obtained $\mathrm{ZrO}_{2}$ nanoparticles were extracted from the cooled products by dissolving sodium salts in distilled water and washing with ethanol, followed by filtration.

The microwave assisted synthesis (MW) of $\mathrm{ZrO}_{2}$ was performed by using the Masterwave BTR (Anton Paar) reactor. The zirconium and cerium salts were dissolved in distilled water $(0.25 \mathrm{~mol} / \mathrm{L})$ and stirred for $30 \mathrm{~min}$. Then glycine water solution was added (molar concentration of glycine/metal atoms was $4: 1$ ). The prepared mixture was heated in the microwave reactor at $160-180{ }^{\circ} \mathrm{C}$ during

\footnotetext{
* Corresponding author. Tel.: +371-29450343.

E-mail address: jgrabis@rtu.lv (J. Grabis)
} 
20 min with continuous stirring. The obtained particles were extracted by filtration and washed with distilled water and ethanol.

For sol-gel combustion (SG) synthesis [6] $\mathrm{ZrOCl}_{2} .8 \mathrm{H}_{2} \mathrm{O}$ was dissolved in distilled water and $\mathrm{HNO}_{3}$ was added to replace $\mathrm{Cl}^{-}$ions. Mixture was stirred for $30 \mathrm{~min}$ at $80^{\circ} \mathrm{C}$ and then a definite amount of $\mathrm{Ce}\left(\mathrm{NO}_{3}\right)_{2} \cdot 6 \mathrm{H}_{2} \mathrm{O}$ water solution was added. Concentration of the solution was $0.25 \mathrm{~mol} / \mathrm{L}$. Additionally solution of glycine and $\mathrm{HNO}_{3}$ was added in order to reach the molar ratio metals/glycine $=0.5$ and glycine $/ \mathrm{NO}_{3}{ }^{-}=0.7$. The prepared solution was calcinated up to $120-130{ }^{\circ} \mathrm{C}$ on a hot plate until a dark viscous gel was formed and finally burned. The reaction product was calcinated at $400{ }^{\circ} \mathrm{C}$ for $2 \mathrm{~h}$.

All prepared samples of ceria-stabilized zirconia were calcinated up to $1000{ }^{\circ} \mathrm{C}$ temperature in order to examine their thermal stability and phase transition.

The nanocrystalline powders were pressed into graphite dies with diameter of $20 \mathrm{~mm}$ and densified in vacuum at $1200-1500{ }^{\circ} \mathrm{C}$ and pressure of $30 \mathrm{MPa}$ using the spark plasma sintering (SPS) technique (SPS-825.CE). The phase composition of the powders was determined by the X-ray diffraction (XRD) analysis (Advanced D8, Bruker AXS). Crystallite size $D$ was calculated by using $X$-ray diffraction software Eva12 based on the Scherrer formula. The specific surface area (SSA) of the powders was determined by the argon absorption-desorption method. The average particle size $d$ was calculated from SSA; agglomeration degree of the particles was evaluated from ratio $d / D$ [6]. Density of the bulk materials was determined by using the Archimede's method. Microstructure of the materials was examined by scanning electron microscopy (SEM) LYRA3. Vickers hardness was determined by the identation technique.

\section{RESULTS AND DISCUSSION}

Typical temperature of the microwave, molten salts and sol-gel combustion synthesis and characteristics of the prepared ceria-stabilized zirconia are shown in Table 1.

Table 1. Characteristics of as-prepared $\mathrm{ZrO}_{2}-10 \mathrm{~mol} \% \quad \mathrm{CeO}_{2}$ nanoparticles

\begin{tabular}{|c|c|c|c|c|c|}
\hline $\begin{array}{c}\text { Syn- } \\
\text { thesis } \\
\text { method }\end{array}$ & $\begin{array}{c}\text { Synthesis } \\
\text { tempe- } \\
\text { rature, }{ }^{\circ} \mathrm{C}\end{array}$ & SSA, $\mathrm{m}^{2} / \mathrm{g}$ & $\begin{array}{c}\text { Crystallite } \\
\text { size } D, \\
\mathrm{~nm}\end{array}$ & $\begin{array}{c}\text { Average } \\
\text { particle } \\
\text { size } d, \\
\mathrm{~nm}\end{array}$ & $\begin{array}{c}\text { Ratio } \\
d / D\end{array}$ \\
\hline MW & 170 & $120.2 \pm 0.6$ & $3.2 \pm 0.4$ & $7.8 \pm 0.5$ & 2.4 \\
\hline MW & 180 & $92.1 \pm 0.5$ & $3.6 \pm 0.4$ & $10.2 \pm 0.5$ & 2.8 \\
\hline MS & 400 & $123.1 \pm 0.6$ & $5.3 \pm 0.4$ & $7.6 \pm 0.5$ & 1.4 \\
\hline MS & 600 & $109.0 \pm 0.5$ & $5.8 \pm 0.4$ & $8.5 \pm 0.5$ & 1.5 \\
\hline SG & 500 & $48.2 \pm 0.3$ & $8.2 \pm 0.3$ & $19.5 \pm 0.4$ & 2.1 \\
\hline SG & 600 & $39.2 \pm 0.3$ & $9.4 \pm 0.3$ & $24.6 \pm 0.4$ & 2.6 \\
\hline
\end{tabular}

The nanoparticles prepared by MW and MS synthesis had higher SSA and lower crystallite size with respect to the powders obtained by the SG process. The SSA for all processes depended on the temperature.

However, nanoparticles prepared by the molten salt synthesis method had highest SSA despite the higher temperature of synthesis as that of the microwave assisted process. It indicated that liquid salts prevented growth of the ceria-zirconia nanoparticles.

The dependence of SSA of the nanoparticles prepared by MS synthesis on ratio metals/salts (Fig. 1) confirmed influence of salts. Decrease of oxide content in mixture remarkably increased the SSA of nanoparticles prepared by the MS method.

The crystallite size of as-prepared by the MW and MS methods nanoparticles were in the range of 3.2-5.8 nm but the crystallite size of nanoparticles prepared by SG method was in the range of $8.2-9.4 \mathrm{~nm}$.

These data indicated that the crystallite size of the particles depended on synthesis method, synthesis temperature and time. Low temperature and short duration of the MW process (20 min) promoted formation of smaller crystallites.

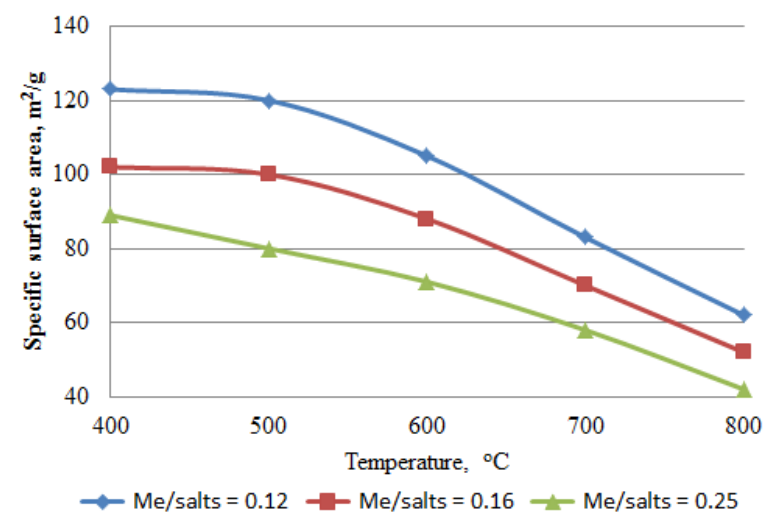

Fig. 1. Dependence of the SSA of the samples produced by MS synthesis on the calcination temperature for different ratio metal/salts (Me/salts)

Values of the average particle size $d$ calculated from SSA exceeded the determined crystallite size $D$ 1.4-2.6 times. The ratio $d / D$ that indicated degree of agglomeration [6] was smaller for nanoparticles prepared by the MS method because liquid salts as well as repeated washing of the products with water and ethanol prevented agglomeration and decreased its degree.

XRD patterns of as-prepared nanoparticles showed broad diffraction patterns of the ceria-stabilized tetragonal phase of zirconia (Fig. 2).

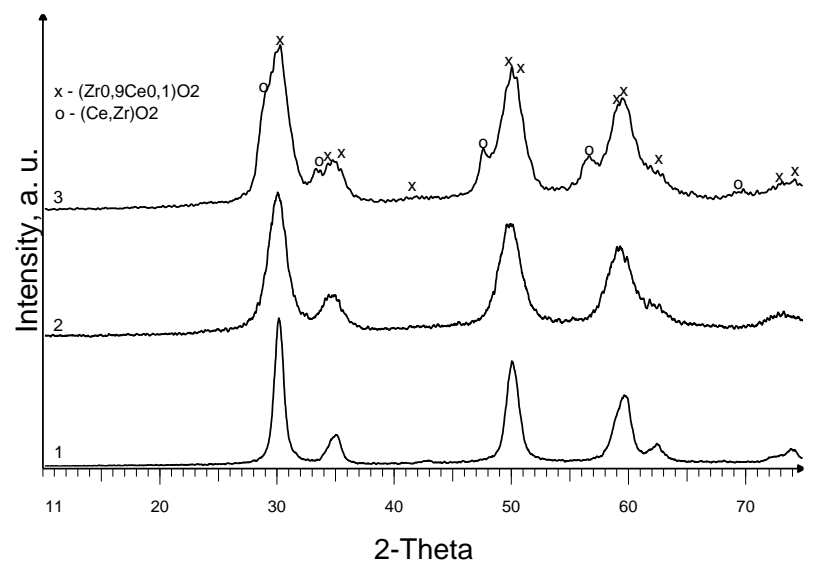

Fig. 2. XRD patterns of the as-prepared $\mathrm{ZrO}_{2}$ nanoparticles stabilized with $10 \mathrm{~mol} \%$ of ceria using sol-gel (1), microwave (2), and molten salts (3) synthesis.

However, the XRD patterns of MS nanoparticles indicated presence of two ceria-stabilized zirconia phases with different content of ceria. Obviously, the presence of 
salts in the MS process inhibited interaction of zirconia and ceria. Similar XRD patterns showed zirconia nanoparticles stabilized with 15 mol\% ceria.

Additional calcination of the as-prepared nanoparticles led to narrowing diffraction maxima of XRD patterns and minimal transformation of tetragonal phase of zirconia to monoclinic (Fig. 3) for nanopowders prepared by MW and MS synthesis indicating the presence of transformable tetragonal zirconia phase in as-prepared particles.

The noticeable formation of monoclinic zirconia phase in nanopowders prepared by SG synthesis started at $850-900{ }^{\circ} \mathrm{C}$. Content of monoclinic phase of zirconia reached $6 \%$ at calcination temperature $1000{ }^{\circ} \mathrm{C}$.

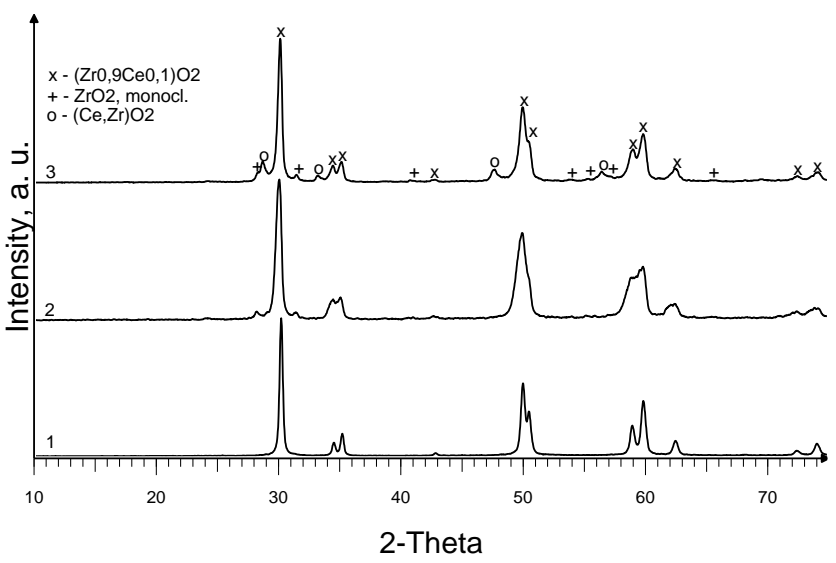

Fig. 3. XRD patterns of calcinated at $800{ }^{\circ} \mathrm{C}$ for $2 \mathrm{~h}$ stabilized with $10 \mathrm{~mol} \%$ of ceria using sol-gel (1), microwave (2), and molten salts (3) synthesis

Besides phase composition of the nanoparticles, additional calcination strongly affected the SSA and crystallite size of nanoparticles (Fig. 4).

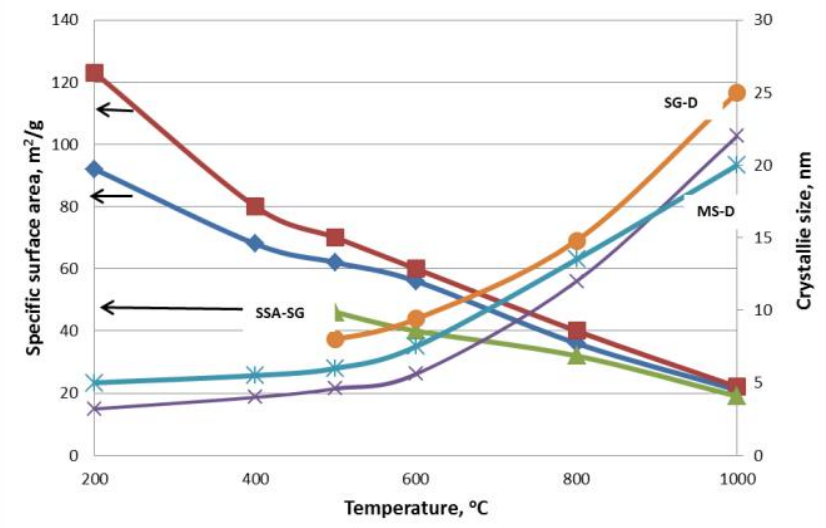

Fig. 4. Dependence of the specific surface area (SSA-MW, SSAMS, SSA-SG) and crystallite size (MW-D, MS-D, SG-D) prepared by MW, MS, SG synthesis on synthesis temperature

Dependence of SSA and crystallite size on calcination temperature was similar for all samples. At temperature of $1000{ }^{\circ} \mathrm{C}$ the SSA of all nanoparticles was in the range of $18-21 \mathrm{~m}^{2} / \mathrm{g}$, and the crystallite size was in the range of 20-26 nm; powders prepared by SG synthesis had the higher crystallite size.

Using spark plasma sintering densification of well crystalline ceria-stabilized zirconia nanoparticles calcinated at temperature $400{ }^{\circ} \mathrm{C}, 600{ }^{\circ} \mathrm{C}$ and $800{ }^{\circ} \mathrm{C}$ started at $850-880^{\circ} \mathrm{C}$ and final shrinkage was observed at $1260-1310^{\circ} \mathrm{C}$ (Table 2) depending on the specific surface area and synthesis method.

Table 2. Temperature of shrinkage and relative density of ceria stabilized zirconia samples during SPS process

\begin{tabular}{|c|c|c|c|c|c|}
\hline \multirow{2}{*}{$\begin{array}{c}\text { Syn- } \\
\text { thesis }\end{array}$} & $\begin{array}{c}\text { Calcination } \\
\text { tempe- } \\
\text { rature, }{ }^{\circ} \mathrm{C}\end{array}$ & \multirow{2}{*}{$\begin{array}{c}\text { SSA, } \\
\mathrm{m}^{2} / \mathrm{g}\end{array}$} & \multicolumn{2}{|c|}{$\begin{array}{c}\text { Temperature of } \\
\text { shrinkage, }\end{array}$} & \multirow{2}{*}{$\begin{array}{c}\text { Relative } \\
\text { density, } \\
\%\end{array}$} \\
\cline { 4 - 5 } & & starting & final & \\
\hline MW & 400 & 71.2 & 860 & 1280 & 97.2 \\
\hline MW & 800 & 41.0 & 870 & 1290 & 97.0 \\
\hline MS & 400 & 81.0 & 850 & 1300 & 96.4 \\
\hline MS & 800 & 40.0 & 880 & 1310 & 96.0 \\
\hline SG & 600 & 39.0 & 850 & 1260 & 95.8 \\
\hline SG & 800 & 31.0 & 860 & 1280 & 95.2 \\
\hline
\end{tabular}

Characteristic feature of sintering behavior and density of the samples prepared by each method were dependence of the specific surface area determined by calcination temperature of precursors. However, sintering of the samples prepared by microwave assisted, molten salts and sol-gel combustion method with very close specific surface area $-41.0 ; 40.0 ; 39.0 \mathrm{~m}^{2} / \mathrm{g}$ respectively - showed different density of the bulk materials. Obviously, the sintering was influenced also by different phase composition (Fig. 3) and particle size distribution, degree of agglomeration.

The increase of sintering temperature up to $1500{ }^{\circ} \mathrm{C}$ and holding time from 3 to $6 \mathrm{~min}$ had insignificant influence on the sintering process and density of the samples.

The relative density of the samples was in the range of 95.2-97.2\% depending on synthesis method and the SSA. The lower density of materials sintered from MS synthesis nanoparticles can be explained by presence solid solution of $\mathrm{Zr}-\mathrm{Ce}-\mathrm{O}$ and reduced content of $\mathrm{t}-\mathrm{ZrO}_{2}(6 \%)$ due to reduction of oxides [10]. The sintered $\mathrm{MW}$ and $\mathrm{SG}$ samples contained $\mathrm{m}-\mathrm{ZrO}_{2}$ and $\mathrm{t}-\mathrm{ZrO}_{2}(34-42 \%)$ depending on the content of $\mathrm{CeO}_{2}$. The density of SG materials was influenced by the lower specific surface of area of the powders.

The microstructure of the sintered bulk materials showed well shaped grains with the size in the range of $0.44-1.10 \mu \mathrm{m}$ (Fig. 5) independently on preparation method of the nanoparticles.

The obtained grain size of sintered materials was smaller than that obtained by pressureless sintering of ceriastabilized zirconia at temperature $1400{ }^{\circ} \mathrm{C}$ for $2 \mathrm{~h}(2 \mu \mathrm{m})$ prepared by the spray-drying techniques [2].

The relative high grain-size of the manufactured bulk materials despite of low particle size of the precursors could be explained by presence of particle aggregates that accelerated growth of the grains during sintering.

Vickers hardness of bulk ceria-stabilized zirconia materials sintered from nanoparticles prepared by MW, MS and SG was 7.8, 6.6, and 7.0 GPa, respectively. The low hardness of material obtained from MS synthesis is related to low density of nanoparticles.

From results followed that all applied synthesis methods allowed to prepare ceria stabilized zirconia nanoparticles. However, MS synthesis led to formation of $\mathrm{Zr}-\mathrm{Ce}-\mathrm{O}$ solid solution as extra phase. Presence of this phase influenced sintering final density of materials and reduced strongly content of $\mathrm{t}-\mathrm{ZrO}_{2}$. 

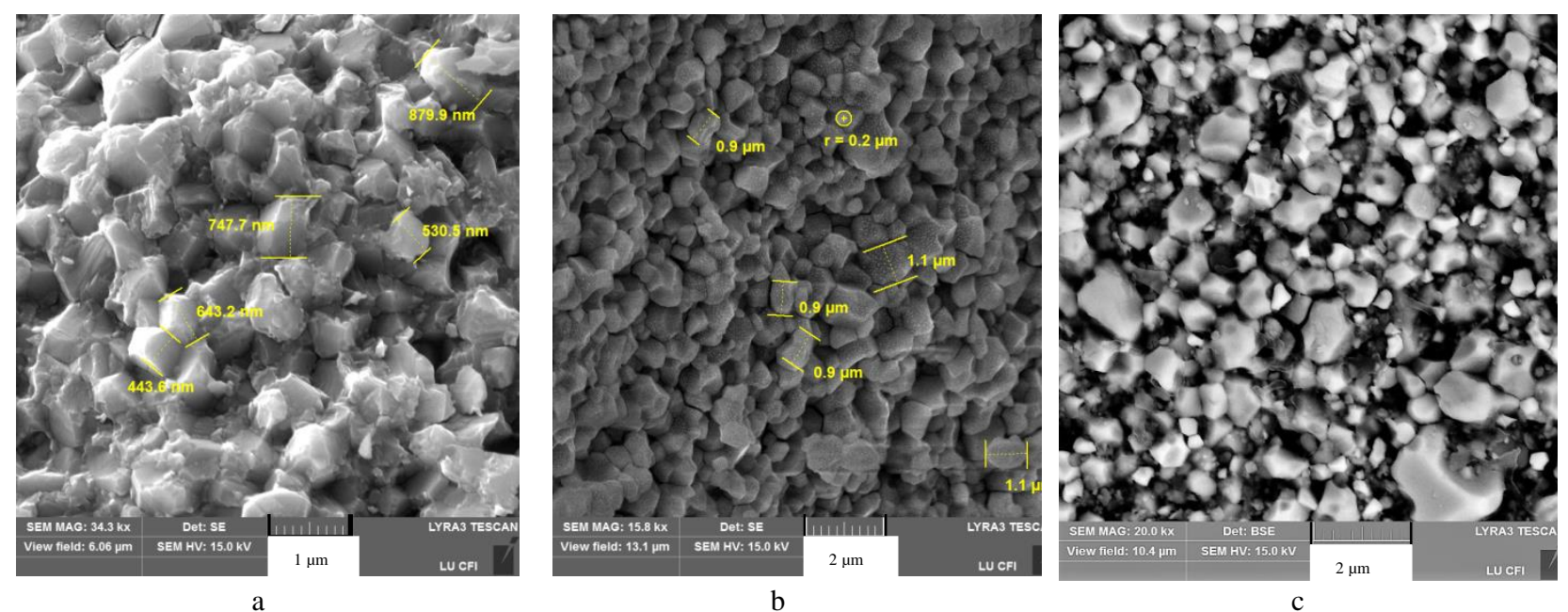

Fig. 5. Fracture surface micrographs of the sintered nanoparticles prepared by: $a-M W ; b-S G$ synthesis; $c-$ MS synthesis

Fast spark plasma sintering of MW and SG samples containing $\mathrm{t}-\mathrm{ZrO}_{2}$ phase at relatively low temperature limited reduction of oxides [10] and insured good sinterability and density of the bulk materials.

\section{CONCLUSIONS}

The developed microwave assisted and molten salts synthesis methods allow to prepare ceria-stabilized zirconia nanoparticles with crystallite size in the range of $3.2-5.8 \mathrm{~nm}$ what is smaller than that $(8.2-9.4 \mathrm{~nm})$ obtained by sol-gel combustion synthesis. Molten salts synthesis promotes formation of cubic solid solution of $\mathrm{Zr}$-Ce-O.

The spark plasma sintering of obtained nanoparticles at $1280-1310{ }^{\circ} \mathrm{C}$ allows produce fine-grained materials. Materials obtained from nanoparticles prepared by microwave assisted synthesis have better sinterability and higher density.

The main advantages of the microwave preparation method of ceria-stabilized zirconia are simplicity, low temperature $\left(170-180{ }^{\circ} \mathrm{C}\right)$ and duration $(20 \mathrm{~min})$ of the process.

\section{Acknowledgments}

The research was supported by State research programme IMIS ${ }^{2}$.

\section{REFERENCES}

1. Lin, J.D., Duh, J.G., Lo, C.L. Mechanical Properties and Resistance to Hydrothermal Aging of Ceria And YttriaDoped Tetragonal Zirconia Ceramics Materials Chemistry and Physics 77 (3) 2003: pp. 808-818. https://doi.org/10.1016/S0254-0584(02)00161-X

2. Sharma, S.C., Gokhale, N.M., Dayal, R., Lal, R. Synthesis, Microstructure and Mechanical Properties of Ceria Stabilized Tetragonal Zirconia Prepared by Spray Drying Technique Bulletin of Material Science 25 (1) 2002: pp. 15-20. https://doi.org/10.1007/BF02704588

3. Matsuzawa, M., Abe, M., Horibe, S., Sakai, J. The Effect of Reduction on the Mechanical Properties of $\mathrm{CeO}_{2}$ Doped Tetragonal Zirconia Ceramics Acta Materialia 52 (6) 2004: pp. $1675-1682$. https://doi.org/10.1016/j.actamat.2003.12.012

4. Cabanas, A., Darr, J.A., Lester, E., Poliakoff, M. Continuous Hydrothermal Synthesis of Inorganic Materials in a Near-Critical Water Flow Reactor; The One-Step Synthesis Of Nano-Particulate $\mathrm{Ce}_{1-x} \mathrm{Zr}_{x} \mathrm{O}_{2}(x=0-1)$ Solid Solutions Journal of Materials Chemistry 11 (2) 2001: pp. 561-568. https://doi.org/10.1039/b008095k

5. Rossignol, S., Gerard, F., Duprez, D. Effect of the Preparation Method on the Properties of Zirconia-Ceria Materials Journal of Materials Chemistry 9 1999: pp. $1615-1620$.

https://doi.org/10.1039/a900536f

6. Zarkov, A., Stanulis, A., Salkus, T., Kezionis, A., Jasulaitiene, V., $\quad$ Ramanauskas, R., $\quad$ Tautkus, S., Kareiva, A. Synthesis of Nanocrystalline Gadolinium Doped Ceria Via Sol-Gel Combustion and SolGel Synthesis Routes Ceramics International 42 2016: pp. 3972-3988.

https://doi.org/10.1016/j.ceramint.2015.11.066

7. Lascalea, G.E., Lamas, D.G., Perez, L., Cabanillas, E.D., Walsoe de Reca, N.E. Synthesis of $\mathrm{ZrO}_{2}-15 \mathrm{~mol} \% \mathrm{CeO}_{2}$ Nanopowders by a pH-controlled Nitrate-glycine Process Materials Letters 58 (20) 2004: pp. 2456-2460. https://doi.org/10.1016/j.matlet.2004.02.036

8. Zarkov, A., Stanulis, A., Sakaliuniene, J., Butkute, S., Abakeviciene, B., Salkus, T. Tautkus, S., Orliukas, A. F., Tamulevicius, S., Kareiva, A. On the Synthesis of Yttria-stabilized Zirconia: A Comparative Study Journal of Sol-Gel Science and Technology (JSST) 76 2015: pp. 309-319. https://doi.org/10.1007/s10971-015-3778-1

9. Bondioli, F., Bonamartini Corradi, A., Ferrari, A.M., Leonelli, C. Synthesis of Zirconia Nanoparticles in a Continuous-Flow Microwave Reactor The Journal of the American Ceramic Society 91 (11) 2008: pp. 3746-3748. https://doi.org/10.1111/j.1551-2916.2008.02666.x

10. Xu, T., Wang, P., Fang, P., Kan, Y., Chen, L., Vleugels, J., Van der Briest, Omer., Van Landuyt, J. Phase Assembly and Microstructure of CeO-doped $\mathrm{ZrO}_{2}$ Ceramic Prepared by Spark Plasma Sintering Journal of the European Ceramic Society 25 2005: pp. 3437-3442. https://doi.org/10.1016/j.jeurceramsoc.2004.09.004 